\title{
Multiple heterochronic gastrointestinal stromal tumors in the stomach detected 6 years after resection: a case report
}

\author{
Tadahito Yasuda', Kojiro Eto', Naoya Yoshida', Shiro Iwagami', Yukiharu Hiyoshi', Youhei Nagai', \\ Masaaki Iwatsuki ${ }^{1}$, Takatsugu Ishimoto', Yoshifumi Baba', Yuji Miyamoto', Takuya Shiota ${ }^{1}$, Yoshiki Mikami ${ }^{2}$ and \\ Hideo Baba ${ }^{1 *}$
}

\begin{abstract}
Background: To date, only a few cases of multiple GISTs with different clones in different organs have been published. However, a case of multiple GISTs with different clones occurring in a single organ has never been reported.

Case presentation: A 41-year-old patient underwent laparoscopic partial gastrectomy for gastric gastrointestinal stromal tumor (GIST) in 2012. The pathological findings showed high-risk characteristics for recurrence, so he received adjuvant therapy with imatinib for 3 years. In 2018, 3 years after completing the adjuvant therapy, tumor lesions at residual gastric cardia were incidentally identified by follow-up computed tomography (CT). The pathological findings of the tumor biopsy revealed gastric GIST. He underwent secondary laparoscopic partial gastrectomy and was diagnosed with high-risk GIST. Adjuvant therapy with imatinib was restarted immediately. The two gastric GISTs had the same exon 11 mutations in the c-kit gene, but they had different missense mutations. This molecular heterogeneity suggested that they were derived from different origins.

Conclusion: We reported a multiple heterochronic GIST in the stomach detected 6 years after resection. There may be a possibility that another heterochronic GIST will occur in the remnant stomach in the future, so close follow-up will be needed.
\end{abstract}

Keywords: Multiple heterochronic GIST, Adjuvant therapy

\section{Background}

Gastrointestinal stromal tumors (GISTs) are the most common mesenchymal tumor of the gastrointestinal tract originating from cells of Cajal [1], and the estimated annual incidence is 10 to 20 per million. The standard treatment for a primary resectable GIST without distant metastasis is surgery. Adjuvant therapy with imatinib for 3 years is recommended for high-risk GISTs [2].

GISTs are commonly generated as a solitary tumor [3], and multiple GISTs are relatively rare [4], except in

\footnotetext{
* Correspondence: hdobaba@kumamoto-u.ac.jp

${ }^{1}$ Department of Gastroenterology, Graduate School of Medical Science,

Kumamoto University, 1-1-1 Honjo, Kumamoto 860-8556, Japan

Full list of author information is available at the end of the article
}

heredity disorders such as von Recklinghausen disease [5] [6] and Carney's syndrome [7]. In addition, multiple GISTs previously reported synchronously occurred in different organs [8].

Herein, we report a case of multiple heterochronic GISTs with different clones metachronously generated in the stomach. To the best of our knowledge, this is the first case of multiple GISTs with different clones in a single organ.

\section{Case presentation}

A 41-year-old man underwent laparoscopic partial gastrectomy for gastric GIST in 2012. He has no familial history of GIST-rerated heredity disorder. The pathological

\section{Springer Open}

() The Author(s). 2020 Open Access This article is licensed under a Creative Commons Attribution 4.0 International License, which permits use, sharing, adaptation, distribution and reproduction in any medium or format, as long as you give appropriate credit to the original author(s) and the source, provide a link to the Creative Commons licence, and indicate if changes were made. The images or other third party material in this article are included in the article's Creative Commons licence, unless indicated otherwise in a credit line to the material. If material is not included in the article's Creative Commons licence and your intended use is not permitted by statutory regulation or exceeds the permitted use, you will need to obtain permission directly from the copyright holder. To view a copy of this licence, visit http://creativecommons.org/licenses/by/4.0/. 
examination showed the negative resection margins, and there was no heterogeneity. The number of nuclear fissions was $50-70$ with 50 high power fields. Therefore, the pathological findings suggested that the tumor had highrisk characteristics of recurrence according to the modified Fletcher classification (Fig. 1a, b). Thus, he received adjuvant therapy with imatinib for 3 years and follow-up computed tomography (CT) every 6 months. No recurrence and new one occurred afterwards. In 2018, 3 years after the completion of adjuvant therapy, tumor lesions were detected at the gastric cardia with a diameter of 30 $\mathrm{mm}$ via follow-up CT (Fig. 2a). Laboratory data, including tumor markers, were almost within the normal range. Gastroscopic examination showed a submucosal tumor at the gastric cardia with a diameter of $20 \mathrm{~mm}$ (Fig. 2b). The tumor was located away from the resection margin of the previous surgery, which suggested that the tumor was not a local recurrence but a newly generated tumor. Immunohistochemistry of the biopsy from the tumor showed a positive KIT protein, and the tumor was diagnosed as a gastric GIST. Positron emission tomography (PET) CT showed abnormal high uptake at gastric cardia (Fig. 2c).

He finally underwent laparoscopic partial gastrectomy again. The pathological examination showed KIT $(+)$, CD34 (+), desmin (-), and S-100 (-) in the tumor. The number of nuclear fissions was $50-70$ with 50 highpower fields. Therefore, the tumor was diagnosed as a high-risk gastric GIST (Fig. 2d).

We conducted a mutation analysis on both gastric GISTs. They had the same exon 11 mutations in the ckit gene but different missense mutations. The first GIST had the W557_V559 > ST codon mutation of exon 11, whereas the second GIST had the W557_K558 > ST codon mutation of exon 11. This molecular heterogeneity suggested that they were derived from different origins. Therefore, we diagnosed multiple heterochronic GISTs in the stomach. Consequently, adjuvant therapy with imatinib was restarted for the second time.

\section{Discussion}

To date, only a few cases of multiple GISTs with different clones in different organs have been published [8-10]. However, a case of multiple GISTs with different clones occurring in a single organ has never been reported. In the present case, mutation analysis of the c-kit gene showed that the two metachronous GISTs had different missense mutations of exon 11.

In the present case, we diagnosed the second GIST as a second primary GIST with different mutations, not local recurrence. Therefore, we performed surgical resection and administered subsequent adjuvant chemotherapy with imatinib. If a local recurrence was diagnosed, a second agent could possibly be administered. Our case suggested that mutation analysis of the c-kit gene is integral to precisely diagnosing the origin of multiple metachronous GISTs and assembling an optimal treatment strategy, which can affect the long-term outcome [11].

Unidentified genetic and environmental backgrounds may affect the occurrence of multiple GISTs with different clones. Several reports of multiple synchronous GISTs with different clones may imply the existence of risk factors for GIST occurrence in individual cases. Some cases contingently observed multiple microscopic GISTs with different clones in the stomach resected for other diseases and in a cadaver. Agaimy et al. suggested that these cases may involve multiple etiological factors inducing somatic c-kit or PDGFRA mutations to initiate the microscopic GISTs [8, 12, 13]. Based on the information, there is a possibility that multiple GISTs can be predicted in the future.

In the present case, adjuvant imatinib was administered after resection of the first GIST, which might suppress the incidence of a second GIST. This case may also have these risk factors, such as somatic c-kit or PDGFRA mutations for GIST occurrence. Thus, we must pay careful attention to the third primary GIST in
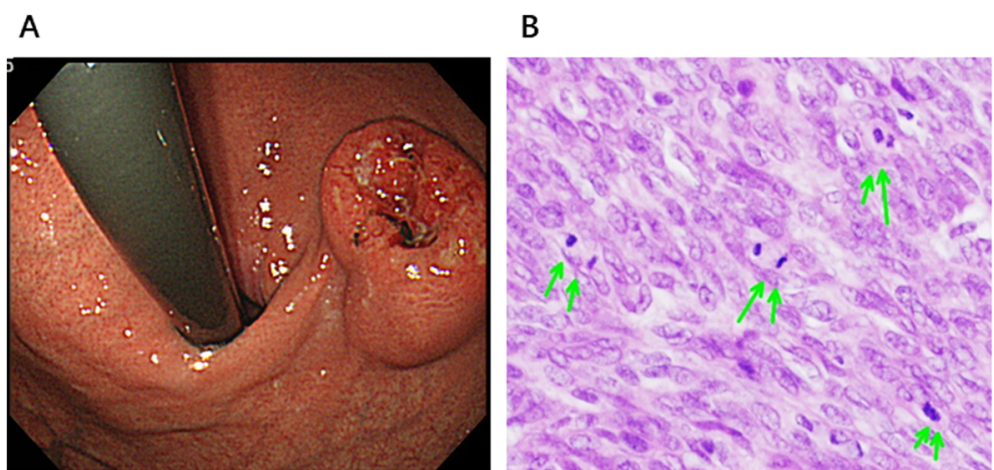

Fig. 1 a Gastrointestinal endoscopic examination showed a submucosal tumor $35 \mathrm{~mm}$ in diameter at the anterior wall of the gastric cardia. b Histological examination of the resected specimens showed a nuclear fission image with 50 high-power fields 
A

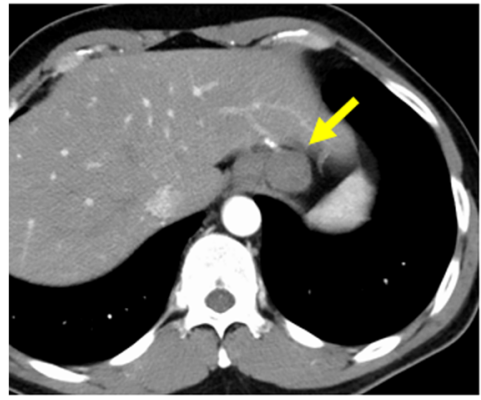

C

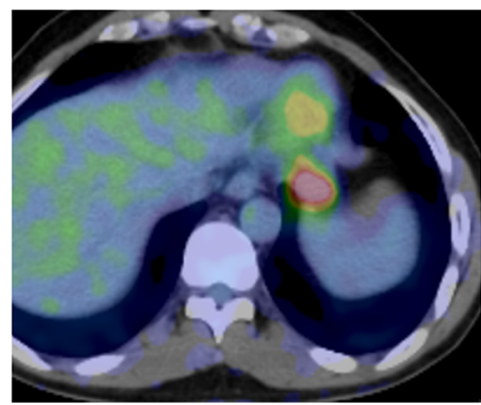

B

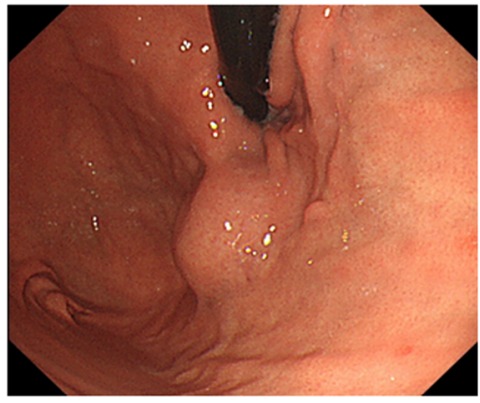

$\mathrm{D}$

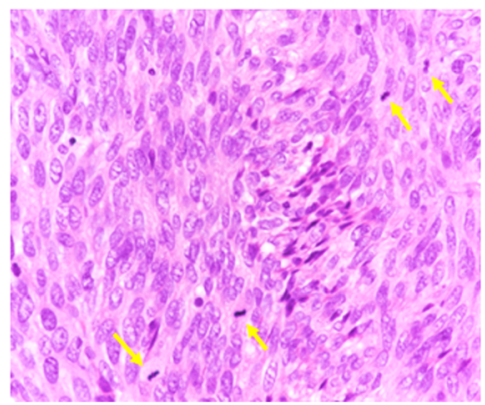

Fig. 2 a Computed tomography showed a gastric tumor measuring $30 \mathrm{~mm}$ in diameter (arrow). b Gastrointestinal endoscopic examination showed a submucosal tumor at the anterior wall of the gastric cardia. c Positron emission tomography-CT (PET-CT) showed abnormal uptake only at the gastric cardia. $\mathbf{d}$ Histological examination of the resected specimens showed a nuclear fission image with $\times 50$ high-power fields

the future, notably after the completion of the second round of adjuvant therapy with imatinib.

\section{Conclusion}

We reported a multiple heterochronic GIST in the stomach detected 6 years after resection. Mutation analysis of the c-kit gene is integral to precisely diagnosing the origin of multiple GISTs and assembling an optimal treatment strategy. Moreover, there may be a possibility that another heterochronic GIST will occur in the remnant stomach in the future; thus, close follow-up will be needed.

\section{Abbreviations}

CT: Computed tomography; GIST: Gastrointestinal stromal tumor; PDGFRA: Platelet-derived growth factor receptor alpha; PET: Positron emission tomography

\section{Acknowledgements}

The authors thank all the people who contributed to this work.

\section{Author's contributions}

TY wrote the initial draft of the manuscript. KE and NY supervised the writing of the manuscript. KE, SI, and TY performed the surgery and followed up the patient. YH, YN, MI, TI, YB, YM, TS, YM, and BB participated in critically revising the manuscript. BB reviewed it and is responsible for the manuscript. All authors have read and approved the final manuscript.

\section{Funding}

Not applicable.

\section{Availability of data and materials}

Data sharing is not applicable to this article as no datasets were generated or analyzed during the current study.
Ethics approval and consent to participate

Not applicable.

\section{Consent for publication}

We obtained consent for publication from the patient.

\section{Competing interests}

The authors declare that they have no competing interests.

\section{Author details}

'Department of Gastroenterology, Graduate School of Medical Science, Kumamoto University, 1-1-1 Honjo, Kumamoto 860-8556, Japan.

${ }^{2}$ Department of Diagnostic Pathology, Kumamoto University Hospital, Kumamoto, Japan, 1-1-1 Honjo, Kumamoto 860-8556, Japan.

Received: 11 January 2020 Accepted: 26 February 2020

Published online: 07 March 2020

\section{References}

1. Liegl-Atzwanger B, Fletcher JA, Fletcher CD. Gastrointestinal stromal tumors. Virchows Arch. 2010;456(2):111-27.

2. Iwatsuki $\mathrm{M}$, et al. Neoadjuvant and adjuvant therapy for gastrointestinal stromal tumors. Ann Gastroenterol Surg. 2019;3(1):43-9.

3. Nilsson B, et al. Gastrointestinal stromal tumors: the incidence, prevalence, clinical course, and prognostication in the preimatinib mesylate era--a population-based study in western Sweden. Cancer. 2005;103(4):821-9.

4. Li K, et al. Multiple gastrointestinal stromal tumors: analysis of clinicopathologic characteristics and prognosis of 20 patients. Cancer Manag Res. 2019;11:7031-8.

5. Takazawa Y, et al. Gastrointestinal stromal tumors of neurofibromatosis type I (von Recklinghausen's disease). Am J Surg Pathol. 2005;29:755-63.

6. Sawalhi $\mathrm{S}$, et al. Behavior of advanced gastrointestinal stromal tumor in a patient with von-Recklinghausen disease: case report. World J Clin Oncol. 2013:4(3):70-4.

7. Carney JA. Carney triad: a syndrome featuring paraganglionic, adrenocortical, and possibly other endocrine tumors. J Clin Endocrinol Metab. 2009;94(10):3656-62. 
8. Tokunaga $\mathrm{M}$, et al. Multiple synchronous sporadic gastrointestinal stromal tumors in the stomach and jejunum. Intern Med. 2018;57(12):1719-23.

9. Comandini D, Damiani A, Pastorino A. Synchronous GISTs associated with multiple sporadic tumors: a case report. Drugs Context. 2017;6:212307.

10. Gasparotto D, et al. Multiple primary sporadic gastrointestinal stromal tumors in the adult: an underestimated entity. Clin Cancer Res. 2008;14(18): 5715-21.

11. Agaimy A, et al. Multiple sporadic gastrointestinal stromal tumours arising at different gastrointestinal sites: pattern of involvement of the muscularis propria as a clue to independent primary GISTs. Virchows Arch. 2009:455(2): 101-8.

12. Kawanowa $\mathrm{K}$, et al. High incidence of microscopic gastrointestinal stromal tumors in the stomach. Hum Pathol. 2006;37(12):1527-35.

13. Agaimy A, et al. Minute gastric sclerosing stromal tumors (GIST tumorlets) are common in adults and frequently show c-KIT mutations. Am J Surg Pathol. 2007;31:113-20.

\section{Publisher's Note}

Springer Nature remains neutral with regard to jurisdictional claims in published maps and institutional affiliations.

\section{Submit your manuscript to a SpringerOpen ${ }^{\circ}$ journal and benefit from:}

- Convenient online submission

- Rigorous peer review

- Open access: articles freely available online

- High visibility within the field

- Retaining the copyright to your article

Submit your next manuscript at $\boldsymbol{\nabla}$ springeropen.com 